\title{
A HISTORICAL STUDY (2007-2015) ON THE ADOPTION OF ONLINE MUSIC COURSES IN THE UNITED STATES
}

\section{Carol Johnson}

University of Melbourne, Southbank, Victoria, Australia, E-mail: carol.johnson@unimelb.edu.au

As we look to forecasting for the future of music education, understanding what has happened historically provides bearing for where we can go, and can elucidate essential elements required to support achievement of these goals. Prior to COVID-19, music programs were shifting away from the traditional music pedagogy of face-to-face teaching to embrace the online learning environment and offer online music courses. However, the extent and magnitude to which online music teaching had taken place in the United States at the bachelor level had yet been identified across years. Using historical research, this study explored 343 of the 657 National Association of Schools of Music (NASM) institutions in the United States. Findings indicate that online semester-length music courses have been offered at an exponential rate of increase since 2012. As of 2016, 40\% of NASM schools were found to provide online music course offerings in their department. These results have substantial implications for music staff and faculty professional development, and undergirds the importance of developing frameworks and strategies for teaching music online.

KEY WORDS: higher education, historical research, online courses, online music pedagogy, teaching music online

\section{INTRODUCTION}

The pervasiveness of academic online learning at the undergraduate and graduate levels in the United States has been reported yearly. In the latest report, Seaman et al. (2018) identified that "31.6\% of all students" (p. 3) take at least one online course per year. Survey data focused on questions that identified perceptions of faculty and administrators regarding the online environment and related topics such as acceptance, rigor, and future projections of use. Specific data were not collected on arts disciplines, such as music. Music schools and conservatories are at a point in history wherein music pedagogy is undergoing a technological revolution; music courses are being taught online and student expectations for technology immersed teaching are growing. Identifying the popularity of online music course offerings would provide documentation for supporting the 
development of online music tools (e.g., assessment tools specific to music skills) and signal the need to develop pedagogical strategies for instructors teaching music online.

This geographically and time-bound historical study was conducted in order to understand the pervasiveness and scale of online bachelor-level music course offerings and identify the relevance for supporting faculty and students regarding teaching and learning music online. Given the sizable data corpus retrieved, this paper focuses on three acute areas: (a) providing an overview of the online music landscape; (b) identifying commonalities in online music course offerings; and (c) highlighting the implications of the identified data trends. Recommendations from this historical study, as outlined subsequently, provide support and suggestions for forecasting the future needs and adoption of online music courses.

\section{HISTORY OF TECHNOLOGY USE IN MUSIC EDUCATION}

During the twentieth century there was a growing prevalence of technology use in music learning, production, and personal consumption. This included technology for amplifying instruments (e.g., electric guitar), sound reinforcement for music performance (e.g., stage microphones), early home listening devices (e.g., radios, record players, and phonographs), and recording technologies. In parallel, technology to support the teaching of music grew during this time. Research evidence (de Vaney \& Butler, 1996) highlighted the development and use of radio broadcasts for teaching music in the early twentieth century. Therefore, it can be suggested that music education has utilized aspects of technology before they were commonly used in academic teaching. In today's postsecondary music classrooms, general technology use in music teaching and learning to support students for music notation, production, recording, and performance is considered common practice. However, due to the rapid development of learning technologies, there are still many opportunities to further the adoption of technology as support mechanisms for music learning. Online learning is a key development in this area.

\section{ONLINE LEARNING}

Specific to online learning, survey findings by Allen \& Seaman (2014) suggested that, each year, over 7.1 million higher education students were enrolled in an academic online course. Since 2003, the regular yearly surveys by Allen \& Seaman have also identified a consistent increase in institutions adopting online courses to their programs. While the percentage of increase has now dipped below two-digit figures, the high of 32\% in 2011 (Allen \& Seaman, 2013) demonstrated the popularity for adopting online course offerings in colleges and universities in the United States.

Brown \& Adler (2008) underline the increased pervasiveness of technology use for learning in both traditional and online classes as students shift to using personal 
technology tools to support their learning (e.g., watching videos, taking photographs, video chats, etc.). However, even though technology is the foundational element for the online environment learning exchange, how learning takes place in online classes can vary widely (Moore et al., 2011; Bowen et al., 2013). While similar learning outcomes are evidenced in the online learning environment when compared to traditional classroom learning environments (Osguthorpe \& Graham, 2003; Tallent-Runnels et al., 2006; Delialioglu \& Yildirim, 2008; Guiller et al., 2008), like the traditional classroom, the online classroom can also be tailored to support unique learning approaches (e.g., inquiry learning, problem-based learning, learner accessibility, etc.). Each online class can be, in itself, a unique learning environment dependent upon various teaching and learning elements incorporated through the online learning design.

The teaching and learning elements found within an online course are often determined at a department or faculty level. Universities use different learning management systems (LMSs) and provide access to different options within their particular system. At the course level, actual online course structures themselves can range from simple archival items in the online course shell to significantly sophisticated interaction. Online classes can contain technologies that enable the classes to be fully asynchronous, synchronous, or a mixture of both. Similarly, pedagogical approaches used by online instructors can be tailored to each instructor. These fundamental elements of online learning suggest that the online classroom is not easily comparable across disciplines.

The use of online technologies in music classes was evidenced as effective learning supports in the research of Draper (2008), Dye (2007), Eakes (2009), and McConville \& Murphy (2017). Each of these studies explored different aspects of technology use for teaching music in the online environment. From these studies, and others, we can see that flexible and accessible learning can be provided for online music students when supported, as outlined by Johnson (2017), with key considerations of online music pedagogy (e.g., social constructivism). Practical aspects considered for online learning in music include synchronous and asynchronous learning activities, video conferencing (i.e., one-to-one online music lessons) for direct teaching, and intuitively designed LMS course areas.

A need to shift the traditional music teaching paradigm has been identified by many music scholars and music education researchers. With the ubiquitousness of technology, and the increasing degree to which each generation becomes more immersed in technology, adopting technology in traditional music classes is necessary (Crawford, 2013). Furthermore, the need to develop online music pedagogy (Bowman, 2014; Lock \& Johnson, 2018) highlights how researchers can address the specific learning demands for music when teaching in the online space. For example, Lock \& Johnson (2018) posited a 
teaching framework for online music instructors to develop their online music courses. Using data from three institutions that teach undergraduate music classes online, the significant elements of design, communication, and assessment were evidenced as paramount for successful student online music course completion. Each of these elements can be represented in multiple ways through the use of various technologies.

While many studies suggest that the use of online learning technologies can benefit student learning, few studies have focused on identifying the extent to which institutions are offering fully online music courses to students. One of the few studies addressing this issue includes the study by Groulx \& Hernly (2010), wherein they identified nine out of 200 accredited American graduate online music programs (i.e., in which more than $80 \%$ of content was taught online). The more recent study by McConville \& Murphy (2017) surveyed Association for Technology in Music Instruction and National Association of Schools of Music (NASM) members through the United States' College Music Symposium. Their two-part study identified an increase in online music course offerings from 67 online music courses in 2013 (as reported by 58 respondents) to 76 courses in 2016 (as reported by 43 respondents). Taken together, these studies suggest that there has been an increase in the utilization of online learning technologies for teaching music courses. However, the extent of this increase, and what types of music classes are being offered online, has not been identified to date. Furthermore, there is limited distribution of research outputs that address the impact of online music courses on the development of online music pedagogy, and consequently on student learning outcomes.

From the lack of data identifying the magnitude of online music courses across the world, one could suggest that the urgency for addressing the topic of online music pedagogy is not urgent or relevant. However, as we have experienced in 2020, there is now more urgency in generating online music courses due to the COVID-19 pandemic. To provide insight into how online music courses can be utilized by various schools and institutions, the following historical study focuses on the adoption of online music course offerings in the United States at NASM schools $(N=657)$. It is noted that a global understanding is warranted for this field, and that this project is only one part to that broader understanding.

\section{HISTORICAL STUDY}

Teaching Bachelor of Music students in a fully online course format is a practice that has been identified as emerging in the United States (Groulx \& Hernly, 2010). However, there is a limited amount of researched evidence identifying the growth rate of online music courses and to what degree music schools are adopting the use of online classes. Therefore, the purpose of this study was to identify the current landscape of online music courses in undergraduate programs at NASM institutions. The research questions that 
guided this inquiry were the following. (a) What online music courses are currently being offered at NASM institutions? (b) What, if any, are the significant changes happening in these offerings over time?

\subsection{Method}

Historical research is an approach that supports a rigorous study of primary archival records to elucidate the past (Howell \& Prevenier, 2001). The research design involves exploring a specific phenomenon through a process that is guided by collecting and examining data from primary sources, evaluating the data sources, and forming conclusions from the data presented (Saucier Lundy, 2008).

Examination of primary records can provide an understanding of the past. In education, the examination of public course records can provide details regarding what courses were offered during specific semesters. Specifically, archival research was deemed appropriate for this study since the research allows for the use of publicly accessible documents (i.e., webpages not blocked by logins or firewalls) of completed courses (i.e., institutional course offerings) to form the data corpus. From this corpus, statistical analyses can be completed to identify course commonalities across institutions, as well as identification of course outliers.

Using a historical approach, this study used website data collection to identify the following. (a) What NASM-accredited music faculties offered online music courses? (b) What music topics are being offered through online courses? (c) How long have NASMaccredited music faculties been providing students with online music course offerings? Publicly accessible course offering data were collected for the years 2015 and 2016 from the institution's available online sources (i.e., institutional course databases) and categorized (e.g., course title, year level, type, etc.).

The quantitative results from the data corpus can be used to understand the use of, and the degree to which, online music courses are being offered by institutions. From these analyses, the findings can be used to show the adoption rate, changes, and commonalities across institutions. While an overall numerical finding of the availability or non-availability of online music courses can be evidenced from such records, why rates increase, decrease, or stay the same can only be inferred. As such, this paper will present the quantitative results and highlight implications and recommendations that are indicative of technology adoption within institutions.

\subsection{Context}

A historical study was initiated to identify the current online music courses available at the bachelor's degree level. The two-phase study (i.e., investigation of a single data set and its 
data subset) explored online undergraduate music offerings available from accredited 2015 NASM schools $(N=657)$. Due to the large number of individual schools in NASM, and the time-consuming nature of locating publicly available online data on individual institutional websites, random sample selection was used.

During Phase One, 343 (52.2\%) schools were randomly selected for inquiry from the 2015 NASM membership base. From the 343 randomly selected schools, data were not publicly available online from 22 school websites (i.e., 6.4\%). Phase Two explored a random sample subset of 63 schools (i.e., $18 \%$ of the random selection) for in-depth detailing of each institution's historical online music course offerings.

How courses are allocated to programs as core and elective courses are dependent upon the institution or department. To prevent misreporting of data, course themes included in the study were based upon institutional allocation. Course themes included: music appreciation (e.g., for non-music majors), music history (i.e., courses specific to music surveys), music fundamentals (e.g., preparatory for music majors), ethnomusicology, research, introduction to music, musicology, arts general (e.g., arts electives), arts education, composition and arranging, and music technology.

Each institution used different terms to identify their classes as being offered $100 \%$ online. For example, some institutions identified their classes as "online," while others used the terms "online distance," "distance," "100\% online," or "fully online." When the researcher gathered data from the public websites, care was taken to ensure that the data collected identified online music courses as those that took place in the online environment for $100 \%$ of the course time. Therefore, blended learning courses (i.e., courses that had some type of face-to-face component) were not considered as $100 \%$ fully online and were not included in the data.

\subsection{Delimitations}

The study was delimited to institutions in the United States accredited by the National Association of Schools of Music $(N=657)$. Delimitations of this study further included the course categorization as deemed by each individual institution. That is, courses were themed according to the identified units (i.e., music history, music theory, musicology, etc.) given by the institution. The allocations of specific courses for music majors and non-music majors could not be identified during data retrieval.

Within a music context, collecting data on the number of music classes and their subject topics offered online can be more challenging; the niche discipline of music and the nature of surveying thousands of music departments. However, it is important to understand the extent to which music is being offered in the online environment since it can suggest how support for online music instructors and students may need to be addressed. 


\section{FINDINGS AND DISCUSSION}

Data from Phase One (i.e., identification of 138 institutions with online music courses) were used to provide the boundary for the random selection subset of 63 institutions in Phase Two. Findings regarding the number and type of offerings are outlined in the following section. Taken together, these findings identify three key items: (a) an overview of online music course topic offered; (b) a subset calculation of online music courses offered across years; and (c) a subset view of course topics offered since 2007.

\subsection{Overview of NASM Schools Providing Online Music Courses}

The findings from Phase One indicated that out of the 343 randomly selected institutions, $138(40.2 \%)$ schools offered some type of fully online music course, while 183 schools $(53.4 \%)$ did not offer online music courses. Of the 343 schools, data regarding online music course offerings were not available from 22 (6.4\%) school websites.

The data findings identified 11 different music topic categories within the online music courses offered, as classified by the institutions themselves. These topics included the following: music history; music appreciation; ethnomusicology; music fundamentals; music theory; composition and arranging; pedagogy and music education; introduction to music; arts and arts education; music technology; and class piano. As outlined in Table 1, the top three categories offered were music history (318 courses; 43.68\%), music appreciation (129 courses; $17.72 \%$ ), and musicology (68 courses; $9.34 \%$ ). As noted previously, all course topics were kept in the original categories assigned by their institutions to prevent misrepresentation of data. While dependent on course content information, it may be that the introduction to music and music fundamental courses could be similar in content to the music appreciation course topic. Combining these course topics would still show music history as the most popular online music course offering and place music appreciation as the second most popular online music course offering.

\subsection{Subset Data: History of Online Music Course Offerings Since 2007}

Data from the subset sample $(n=63)$ identified that, of the institutions within the random sample, online music courses have been offered in U.S. higher education institutions since 2007 t. Figure 1 indicates the positive trajectory of schools' adopting online music courses since 2007. This trajectory is such that it aligns with an exponential rate of increase. That is, the data demonstrate an exponential fit when the $R_{2}=$ value is closer to 1 . The data in Fig. 1 indicate that $R^{2}=0.97$. Based on these data, the year 2012 indicates the start of an exponential growth in schools adding online music course offerings. 
TABLE 1: Online music course topic offerings in 2015

\begin{tabular}{|lcc|}
\hline Course Topic & $\begin{array}{c}\text { Number of } \\
\text { Online Classes }\end{array}$ & Percentage (\%) \\
Music history & 318 & 43.68 \\
Music appreciation & 129 & 17.72 \\
Musicology & 68 & 9.34 \\
Ethnomusicology & 44 & 6.04 \\
Music fundamentals & 39 & 5.36 \\
Music theory & 39 & 5.36 \\
Composition and arranging & 26 & 3.57 \\
Pedagogy and music education & 20 & 2.75 \\
Introduction to music & 16 & 2.20 \\
Arts and arts education & 12 & 1.65 \\
Music technology & 12 & 1.65 \\
Class piano & 5 & 0.69 \\
Total & 728 & 100 \\
\hline
\end{tabular}

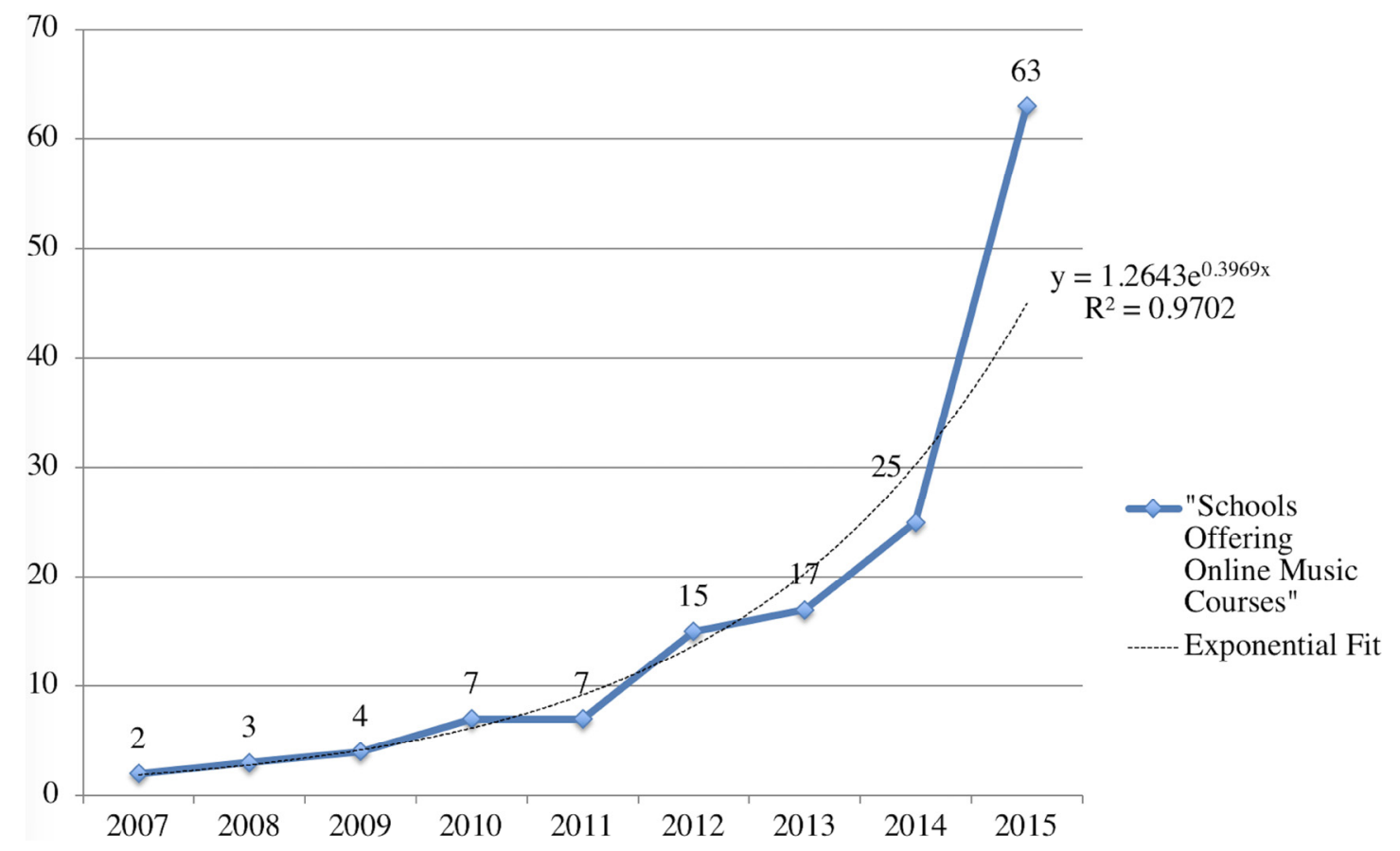

FIG. 1: Number of NASM schools with online bachelor level music courses (within subset data) 
Looking deeper into the data corpus, the number of online music courses offered by each of these institutions can be identified. These data are outlined in Fig. 2, which evidences the exponential rate of an increase in music courses offered fully online. The dotted line in Fig. 2 identifies the exponential fit of the data across the years. From these data, it can be observed that the exponential fit begins at year 2012 and continues through 2015 . The $R 2$ $=$ value confirms this rate of exponential fit, where $R 2=0.97983$.

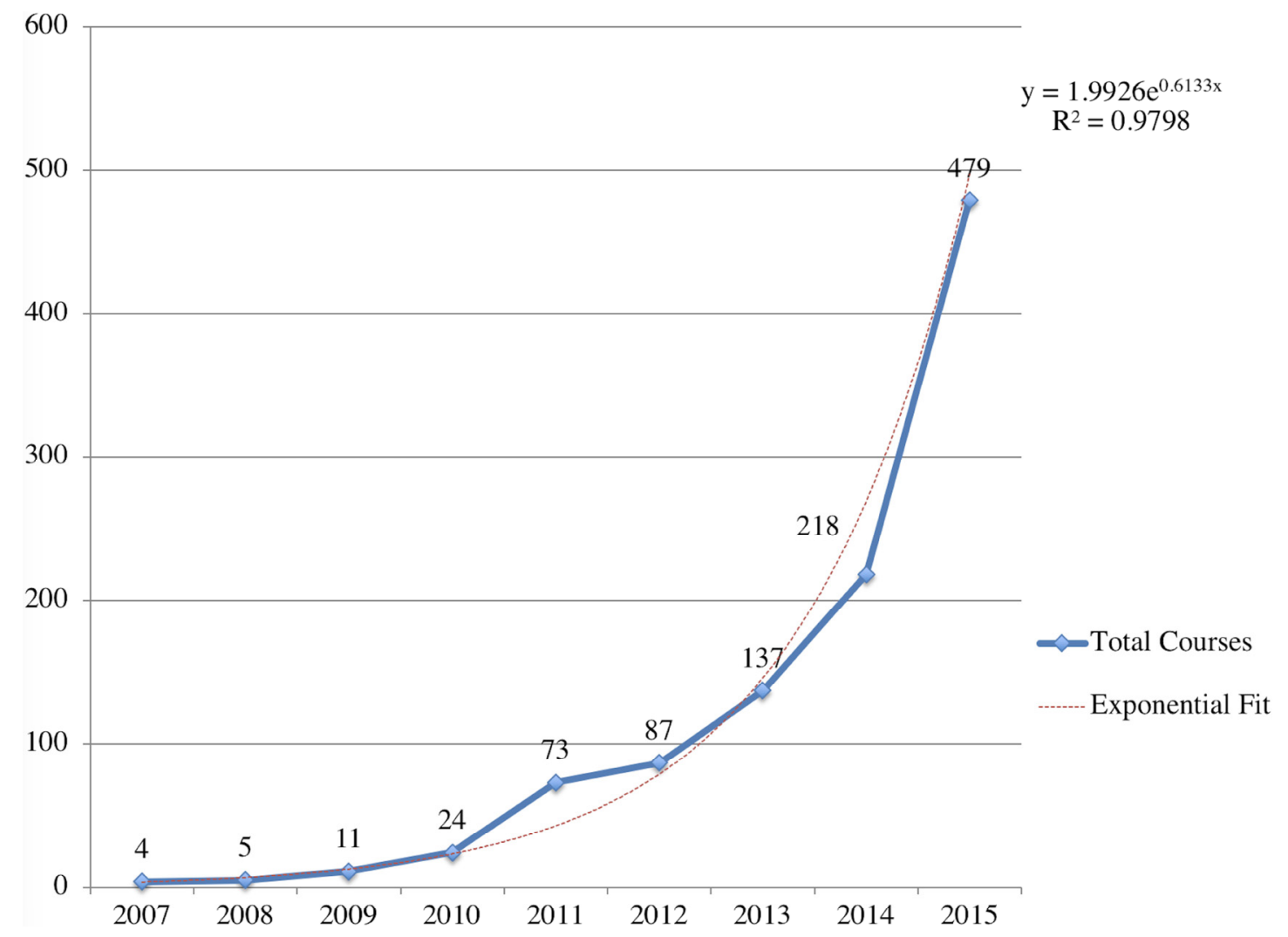

FIG. 2: Exponential rise of online music courses since 2012

\subsection{Subset Data: Course Trend Offerings Since 2007}

Further exploration of the subset's course types and numbers of online music course offerings over this period of time suggested common trends in online music course offerings. These data are in agreement with the 2015 data noted previously. Specifically, music history and the music appreciation-type courses were used as initial online music course offerings among various institutions. These data are represented in Fig. 3, in which the background column represents music history; these columns are found across each year. 


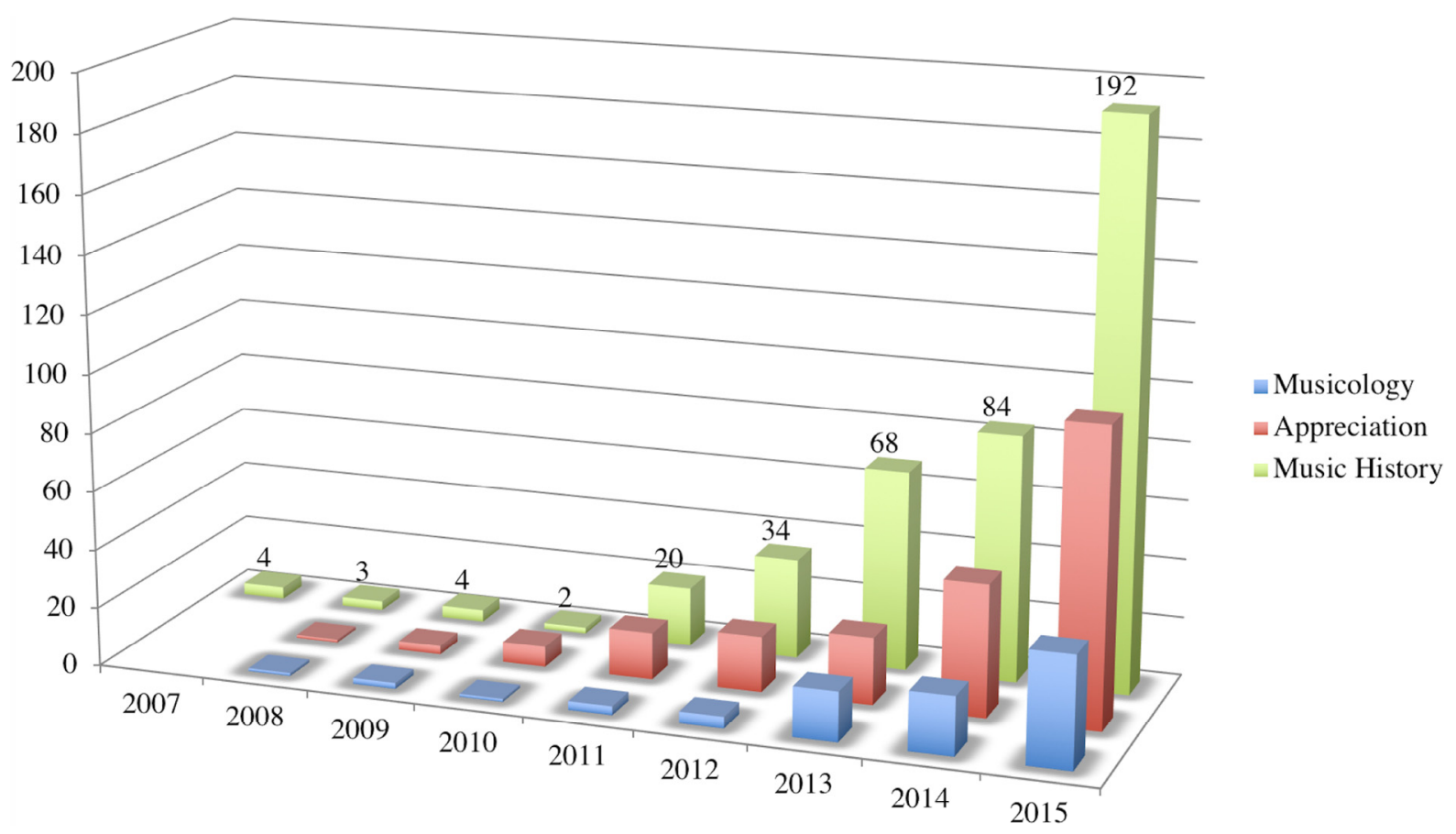

FIG. 3: Top three online music course topics offered since $2007(n=63)$

One noticeable change in the music history pattern was found between the years 2008 and 2011. This evidences the change of type and number of offerings that were represented in the data. While reasons for this difference could be many, it is thought that a decrease in offerings in a particular institution year occurred due to re-designing a course or the development of an online course offering strategy, or because a course was only offered in one semester rather than in both semesters per academic year. This type of pattern was viewed in the minutia data. For example, one institution had one course in 2008; two courses in 2009; one course in 2010; three courses in 2011; two courses in 2012; and six courses in 2013, 2014, and 2015. Another institution started offering online music courses in 2012 with one course in 2012, 10 courses in 2013 and 2014, and 34 courses in 2015. The adoption of online music courses varied across institutions.

The larger data corpus presents interesting details on the overall inclusion of different course topics being taught online. Figure 4 identifies the varied nature of course topic adoption across the years within the subset data. Within Fig. 4, it is evident that music history, music appreciation, and musicology courses were the first topics offered from the data collected. The depth of traditional mode of delivery (i.e., lecture-based modes and not experiential or interactive seminars) may be a form of identifier for which courses are chosen for an online delivery mode. However, the data collected do not seek to qualify why particular course topics were found to be among the first topics different institutions chose to transform into an online course. 


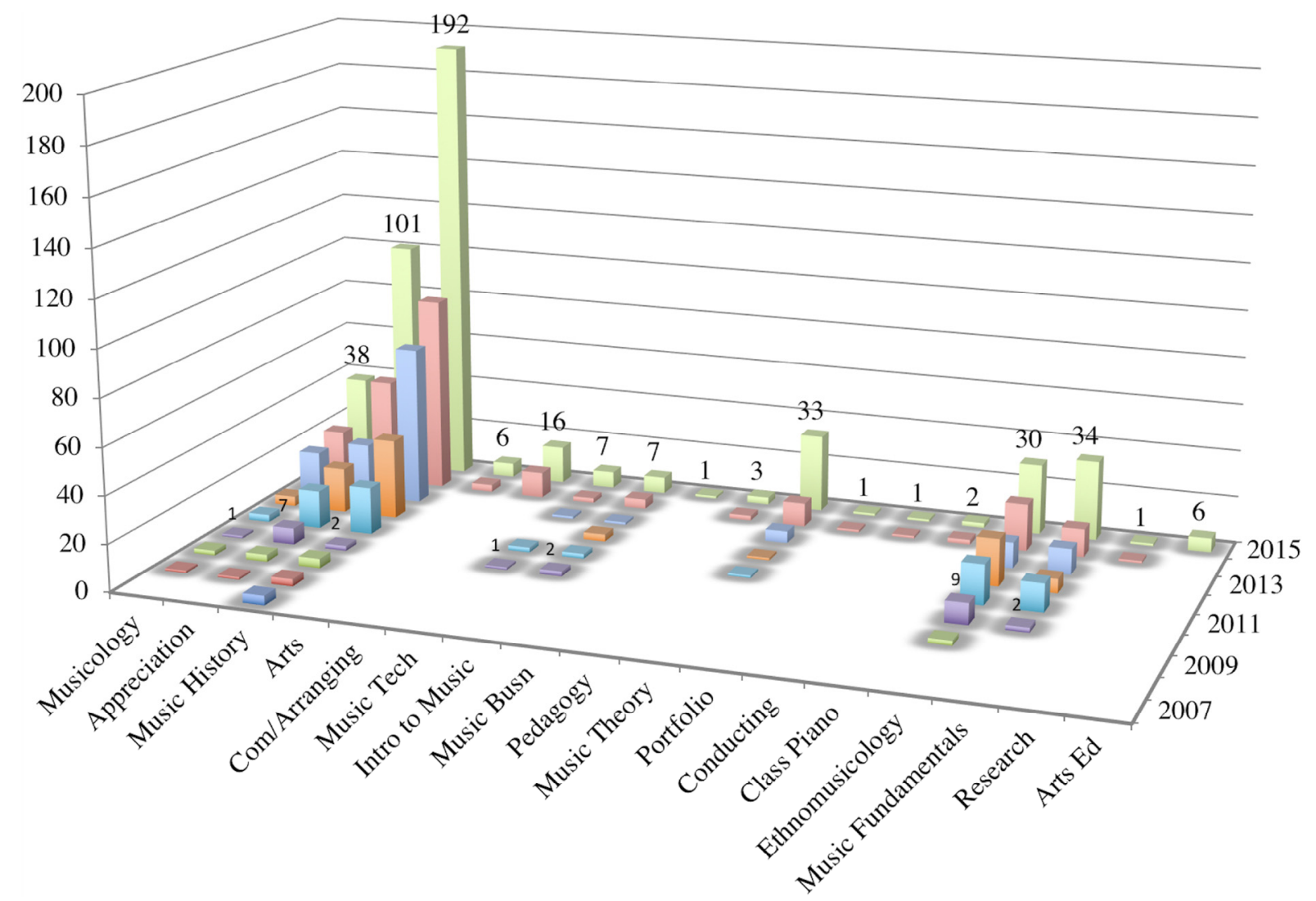

FIG. 4: Online music course offerings since $2007(n=63)$

Finally, the trend data (see Fig. 5) were based on the data set and have been included to evidence the future of online music course offerings. While the results of positive adoption is demonstrated from the trend data, the disruption caused by the 2020 COVID-19 pandemic could not be predicted in the trend data. 


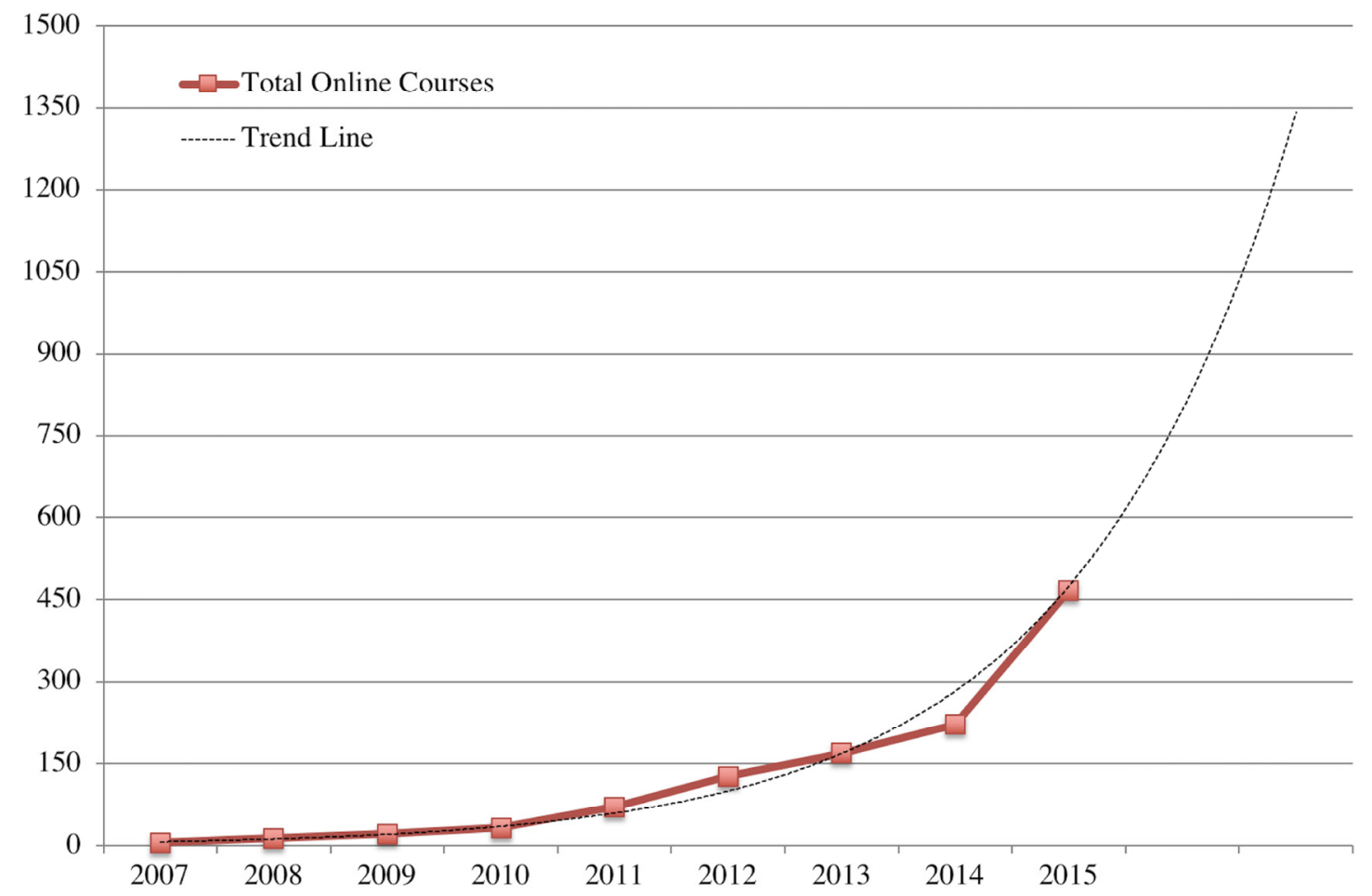

FIG. 5: Trend data based on the data subset $(n=63)$

\section{IMPLICATIONS AND RECOMMENDATIONS}

There are three levels of implications and recommendations to consider from the findings: administrative, instructor, and student levels.

\subsection{Administrative Level}

Within the NASM handbook, how online music pedagogy is to be specifically taught and approached is not addressed (National Association of Schools of Music, 2015). That is, instructors teaching online music courses are not required to have specified training regarding how to teach music in the online environment. Based on music's inherent interactive nature, and that it is not compulsory or common, for higher education music instructors to have pedagogy degrees (Mills, 2004; Fredrickson et al., 2013), institutions and administrators will likely need to provide instructors with educational development opportunities and workshops focused on teaching music online.

While some workshops may be broader in teaching scope (e.g., how to design an online course in a LMS), workshops specific to online music pedagogy and online teacher strategies should be considered. Tertiary music instructors are encouraged to support their process of lifelong learning "through systematic, strategic, scaffolded, and sustained professional development" (Mitchell, 2020, p. 102). Such opportunities not only support instructor understanding of how to teach in the online environment, but will influence 
course retention rates and overall instructor anxiety as identified in the Johnson (2017) multiple case study research of online music programs.

Resulting recommendations at the administrative level surround the financial and leadership obligations to best support faculty for transforming their traditional teaching pedagogy to an online teaching practice. Funding for workshops, mentoring, and technical support are considerations. Furthermore, leadership positions to help signal the different teaching practices involved may be beneficial.

From a departmental or leadership scope, the large number of theoretical music courses being placed online may indicate a need for further inquiry into the course offerings, core courses, and approaches for teaching students music overall. For example, the traditional music history courses may benefit from being re-conceptualized in formats that are not easily available in a face-to-face environment. The teaching of higher education music has radically shifted as a paradigm imposed by 2020's COVID-19 restrictions, and isolation has required many institutions to shift to online teaching. How leadership and music department administrators support instructors and students in learning, as well as practical implementation of social constructivist learning theory in the online environment, and overall online music pedagogy practices, will likely cause a wide-spread pedagogical disruption.

\subsection{Instructor Level}

Based on mathematical trends gathered from the data, it is possible to see that, should courses continue to be added at similar rates, teaching music courses online could become a common offering at many institutions. Should the rate of increase continue according to the data analyzed, the flowing trend line from the historical data is estimated to reach over 1500 online music course offerings by 2020. Given the COVID-19 response and transition of face-to-face classes, the trend line is a moot point.

With the large increase in online music courses, it is apparent that instructors will be required to lead and teach the online courses. This means that instructors will need to adopt the use of online music pedagogy to address how to teach through the unique design, assessment, and communication elements of online teaching (Lock \& Johnson, 2018). Therefore, recommendations for instructors to take part in workshops to develop their online music courses is a practical recommendation. In addition, it is recommended that instructors make use of longer term educational development programs such as mentoring or coaching (Lock, 2018). Such individualized, or one-to-one, programs can better support the transformation to a sustainable and manageable online teaching practice. 


\subsection{Student Level}

With the adoption of online music courses, students may have additional opportunities for elective choices across various universities. The increased acceptance of microcredentialing (Ralston, 2021), and the impact of COVID-19 on online music course offerings, once again signals that students are open to taking music courses online. As noted in the trend data, an increase in NASM institutions offering online music courses was identified. While the anomaly of the vast majority of music classes moving to the online environment due to COVID-19 was not anticipated in the trend data, there was indication that more students would engage in the opportunity to take an online music course. Given this uptake, it can be suggested that students will be using online LMSs and applicable technology tools to support their online music learning. These changes will allow for students to have further flexibility and accessibility to their music learning. As a result, the general music student body will need to have, or gain, the appropriate technology skills and access to music software applications to make the best use of their online music learning.

Based on students' increased use of technology tools and skills sets, it is recommended that students have the opportunity to learn how to prepare themselves for learning online prior to taking an online course. Programs such as online learning orientations (Jones, 2013; Lock et al., 2019) and in-course supplementary online learning modules may be of benefit for supporting students to transition to becoming online learners. The use of these programs for online music students are further areas for research.

\section{FUTURE AREAS FOR RESEARCH}

Finally, as we look to the future of the field of study in online music course offerings, there are three key areas that warrant further research. These main historical research themes target the following: (a) creating a global timeline of online music course uptake from a global perspective; (b) exploration of why online music course offerings were initiated; and (c) what processes or approaches were adopted to facilitate the move toward offering online music courses.

First, it is identified that this study is limited to the United States. Research exploring other countries evidencing the historical progression of accredited music programs or conservatoires adopting online music course offerings would provide a broader global perspective on teaching music online. Focused questions that explore the historical timeline with which other nations offered online Bachelor of Music courses would provide a much needed global perspective.

Second, from this study on data, the subset data suggest that online music courses began to be offered in the United States around the year 2007. Further research needs to be 
completed to confirm this year as the earliest offering and requires addition studies beyond the subset of the 63 institutions explored in this study.

Finally, from a position of technology adoption, research studies that explore why institutions chose to initiate the use of online music course offerings is warranted. Investigating this area of research will likely provide helpful pedagogical implications for how to better plan for and develop complete online music programs at the bachelor level.

\section{CONCLUSIONS}

The data findings from this study evidence that online music courses are being offered at a significant exponential rate of increase. Furthermore, these data strongly suggest that online music courses in undergraduate programs will likely continue to increase. As a result of these findings, practical recommendations include the following: the need for administrative funding toward educational development for current and future online music instructors; adoption of online music pedagogy practices by faculty/staff adopting online music pedagogy practices; and development of agile and sustainable supports and resources to assist both faculty/staff and students in learning how to teach and learn in the online environment. Finally, opportunities for further research exist surrounding each recommendation to position online music courses as effective learning opportunities for current and future students.

\section{ACKNOWLEDGMENTS}

I wish to thank Dr. Scott Hawley and Sherry Sanatkaran for the statistical assistance support they provided over the course of this research project.

\section{REFERENCES}

Allen, I. E., \& Seaman, J. (2013). Changing course: Ten years of tracking online education in the United States. Babson Survey Research Group and Quahog Research Group, LLC. https://www.onlinelearningsurvey.com/reports/changingcourse.pdf

Allen, I. E., \& Seaman, J. (2014). Grade change: Tracking online education in the United States. Babson Survey Research Group and Quahog Research Group, LLC. https://www.onlinelearningsurvey.com/reports/gradechange.pdf

Bowen, W. G., Chingos, M. M., Lack, K. A., \& Nygren, T. I. (2013). Online learning in higher education: Randomized trial compares hybrid learning to traditional course. Education Next, 13(2), 58-65.

Bowman, J. (2014). Online learning in music: Foundations, frameworks, and practices. Oxford University Press. 
Brown, J. S., \& Adler, R. P. (2008). Minds on fire: Open education, the long tail, and learning 2.0. EDUCAUSE Review, 43(1), 16-32. http://www.educause.edu/ero/article/ minds-fire-open-education-long-tail-and-learning-20

Crawford, R. (2013). Evolving technologies require educational policy change: Music education for the 21st century. Australasian Journal of Educational Technology, 29(5), 717 -734 .

Delialioglu, O., \& Yildirim, Z. (2008). Design and development of a technology enhanced hybrid instruction based on MOLTA model: Its effectiveness in comparison to traditional instruction. Computers \& Education, 51(1) ,474-483.

de Vaney, A., \& Butler, R. (1996). Voices of the founders: Early discourse in educational technology. In D. H. Jonassen (Ed.), Handbook of research for educational communications and technology: A project of the Association for Educational Communications and Technology. Macmillan Library Reference. http://members.aect.org/ edtech/ed1/01/index.html

Draper, P. (2008). Music two-point zero: Music, technology and digital independence. Journal of Music, Technology and Education, 1(2-3), 137-152.

Dye, K. (2007). Applied music in an online environment using desktop videoconferencing [Doctoral dissertation]. ProQuest Dissertations and Theses Database (UMI No.3259242).

Eakes, K. (2009). A Comparison of a sociocultural and chronological approach to music appreciation in face-to-face and online instructional formats (Publication No. AAT 3365532) [Unpublished doctoral dissertation, Auburn University].

Fredrickson, W. E., Moore, C., \& Gavin, R. (2013). Attitudes of select music performance faculty toward students teaching private lessons after graduation: A USA pilot study. International Journal of Music Education, 31(3), 331-345. https://doi.org/10.1177/ 0255761413488712

Groulx, T. J., \& Hernly, P. (2010). Online master's degrees in music education: The growing pains of a tool to reach a larger community. Update Applications of Research in Music Education, 28(2), 60-70. https://doi.org/10.1177/8755123310361765

Guiller, J., Durndell, A., \& Ross, A. (2008). Peer interaction and critical thinking: Face-toface or online discussion? Learning and Instruction, 18(2), 187-200. https://doi.org/ 10.1016/j.learninstruc.2007.03.001

Howell, M., \& Prevenier, W. (2001). From reliable sources: An introduction to historical methods. Cornell University Press.

Johnson, C. (2017). Teaching music online: Changing pedagogical approach when moving to the online environment. London Review of Education, 15(3), 439-456. https://doi.org/ 10.18546/LRE.15.3.08 
Jones, K. R. (2013). Developing and implementing a mandatory online student orientation. Journal of Asynchronous Learning Networks, 17(1), 43-45.

Lock, J. (2018). Personalizing educational development for online music educators: A coaching approach. In C. Johnson \& V. C. Lamothe (Eds.), Pedagogy development for teaching music online. IGI Publications. https://doi.org/10.4018/978-1-5225-5109-6.ch015 Lock, J., \& Johnson, C. (2018). Playing together: Designing online music courses using a social constructivist framework. In C. Johnson \& V. C. Lamothe (Eds.), Pedagogy development for teaching music online. IGI Publications. https://doi.org/10.4018/978-15225-5109-6.ch009

Lock, J., Johnson, C., Hanson, J., Liu, Y., \& Adlington, A. (2019). Designing an online graduate orientation program: Informed by UDL and studied by design-based research. In S. Gronseth \& E. Dalton (Ed.), Universal access through inclusive instructional design: International perspectives on UDL (pp. 250-257). Routledge. https://doi.org/10.4324/ 9780429328077-7

McConville, B., \& Murphy, B. (2017). What is online? A national survey of course offerings in music and a case study in music theory. College Music Symposium, 57(1), 1-13. https://doi.org/10.18177/sym.2017.57.itm.11345

Mills, J. (2004). Conservatoire students as instrumental teachers. Bulletin of the Council for Research in Music Education, 161/162, 145-153. https://www.jstor.org/stable/ 40319248

Mitchell, A. (2020). A professional development program to facilitate group music performance teaching. In J. Encarnacao \& D. Blom (Eds.), Teaching and evaluating music performance at university: Beyond the conservatory model. Routledge. https://doi.org/ 10.4324/9780429328077-7

Moore, J., Dickson-Deane, C., \& Gaylen, K. (2011). e-Learning, online learning, and distance learning environments: Are they the same? The Internet and Higher Education, 14(2), 129-135. https://doi.org/10.1016/j.iheduc.2010.10.001

National Association of Schools of Music. (2015). NASM handbook. Retrieved July 15, 2015, from https://nasm.arts-accredit.org/accreditation/standards-guidelines/archive/

Osguthorpe, R. T., \& Graham, C. R. (2003). Blended learning environments: Definitions and directions. Quarterly Review of Distance Education, 4(3), 227-233.

Ralston, S. (2021). Higher education's microcredentialing craze: A post-Deweyan critique. Postdigital Science and Education, 3, 83-101. https://doi.org/10.1007/s42438-02000121-8 
Saucier Lundy, K. (2008). Historical Research. In L. Given (Ed.), The SAGE encyclopedia of qualitative research methods (pp. 396-399). SAGE. http://dx.doi.org/10.4135/ 9781412963909.n199

Seaman, J., Allen, I. E., \& Seaman, J. (2018). Grade increase, tracking distance education in the United States. Babson Survey Research Group. https://onlinelearningsurvey.com/ reports/gradeincrease.pdf

Tallent-Runnels, M., Thomas, J., Lan, W., Cooper, S., Ahern, T., Shaw, S., \& Liu, A. (2006). Teaching courses online: A review of the research. Review of Educational Research, 76, 93-135.

$\uparrow$ It is noted that the subset data suggests that 2007 may be the first year online music courses began in the United States. However, due to the nature of a subset, and the random sampling of institutions, institutions within the 2015 NASM membership may have taught online music courses earlier than 2007. 